\title{
Editorial
}

\section{Karl-Heinz Paqué}

\section{Vereinsgeschichte: Erkenntnisse statt Nostalgie}

DOI 10.1515/pwp-2016-0008

\section{Liebe Leserin, lieber Leser,}

unser Verein für Socialpolitik wurde 1872 gegründet. Er hat eine lange und stolze Tradition. Es liegt deshalb nahe, sich auch mit seiner Geschichte zu beschäftigen. Dies wollen wir, beginnend mit dem vorliegenden Heft, gelegentlich tun - in unregelmäßigen Abständen. Ziel ist es dabei nicht, mit Nostalgie auf die Leistungen unserer Altvorderen zurückzublicken, denn dies eignet sich besser für eine Rückschau $\mathrm{zu}$ bestimmten Jubiläumsterminen, vielleicht in sechs Jahren zum 150. Geburtstag des Vereins. Uns geht es stattdessen in den Perspektiven der Wirtschaftspolitik vor allem darum, den Prozess der gesellschaftlichen und politischen Weiterentwicklung von Arbeitsschwerpunkten und Themen nachzuvollziehen und zu verstehen. Wir hoffen, dass sich daraus Erkenntnisse ergeben, die auch heute noch von zentraler Bedeutung sind.

Den ersten historischen Rückblick in diesem Geiste liefert Dieter Sadowski im vorliegenden Heft. In der Rubrik Aus dem Verein für Socialpolitik schildert er die Genese des Bildungspolitischen Ausschusses, der 1975 seine Arbeit aufnahm und inzwischen auf eine Geschichte von vier Jahrzehnten zurückblicken kann. Der Ausschuss wurde gegründet, als die stürmische Wachstumsphase der deutschen Wirtschaft mit der ersten Ölkrise 1973 und der darauffolgenden schweren Rezession zu Ende gekommen war. Es begann damals in der volkswirtschaftlichen Profession ein neues Nachdenken über die Determinanten des Wachstums und die Engpässe des Arbeitsmarktes. Dadurch rückte die Bildung in den Vordergrund des Interesses. Diesen Platz hat sie bis heute nicht geräumt, zu Recht. Die Bildungsökonomik ist ein fester Bestandteil der wirtschaftswissenschaftlichen Lehre und Forschung.

Ansonsten bewegt sich das vorliegende Heft im üblichen Rahmen. In der Rubrik Wissenschaft im Überblick fasst Felix Bierbrauer die Theorie der optimalen Besteuerung und deren Weiterentwicklung seit der Jahrtausend-

*Kontaktperson: Karl-Heinz Paqué, Otto-von-Guericke-Universität Magdeburg, E-Mail: paque@ovgu.de

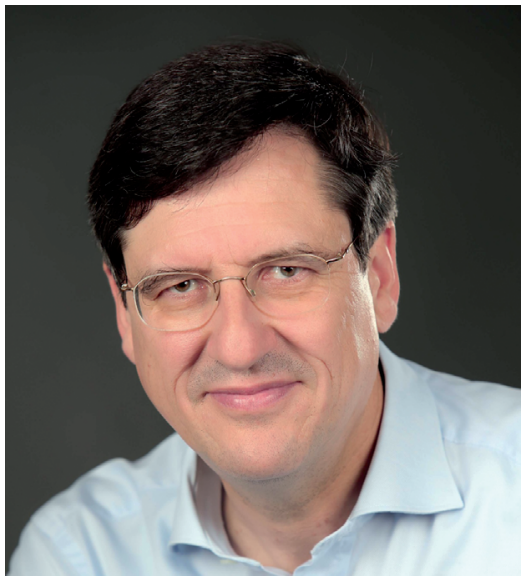

wende zusammen. In der Rubrik Das Gespräch geht es um das vielleicht politisch brisanteste Thema des vergangenen und des laufenden Jahres im deutschsprachigen Raum: Zuwanderung. Der in London tätige Migrationsforscher Christian Dustmann nimmt im Gespräch mit Karen Horn Stellung zu Motiven der Flucht und Wanderung, zur Integrationskraft des Arbeitsmarktes, zu den nötigen Reformen und dem politischen Rechtsruck, der zu beobachten ist. Alles in allem ist sein Ausblick optimistisch - vorausgesetzt, die politisch Verantwortlichen nutzen den Druck zur Veränderung konstruktiv.

Das Thema Zuwanderung setzt sich in der Rubrik Beiträge aus der Forschung fort: Holger Hinte, Ulf Rinne und Klaus F. Zimmermann plädieren für ein aktives Auswahlverfahren für Zuwanderer aus nichteuropäischen Staaten, ein sogenanntes Punktesystem. Weitere Themen sind die Vermögensverteilung in Deutschland, in einem Beitrag von Giacomo Corneo, Tim Bönke und Christian Westermeier, sowie die Gesundheitswirtschaft als Produktivitätsmotor, in einem Beitrag von Alexander Karmann, Felix Rösel und Markus Schneider. Den Abschluss der Rubrik bildet ein Kommentar auf einen Beitrag von Carsten Schröder und Peter Grösche, der im vorausgegangenen Heft der Perspektiven der Wirtschaftspolitik unter dem Titel Plädoyer für einen Energiesoli publiziert war. Joachim Weimann antwortet mit einem Plädoyer gegen eine solche Abgabe.

Karl-Heinz Paqué 